\title{
O FIM MUTUALÍSTICO DESINTERESSADO OU ALTRUÍSTA DAS COOPERATIVAS DE SOLIDARIEDADE SOCIAL
}

\author{
Deolinda Meira \\ Professora Coordenadora \\ CEOS.PP - ISCAP - P. Porto
}

\section{RESUMEN}

Las cooperativas de solidaridad social persiguen, principal o exclusivamente, un fin mutualista desinteresado o altruista, que el legislador denomina "fines de solidaridad social". El objetivo de estas cooperativas es lograr una clara misión de asistencia en situaciones de vulnerabilidad social y económica, dando expresión a los valores de altruismo y solidaridad. Esto justifica que su régimen jurídico tenga ciertas peculiaridades, tanto en lo que se refiere a las categorías de miembros, la estructura organizativa y el régimen económico. Estas cooperativas se caracterizan por la heterogeneidad de sus miembros, lo que exige la definición de normas que permitan una gestión verdaderamente participativa y democrática, y en este sentido se requieren cambios en el régimen jurídico vigente. El régimen económico es plenamente apropiado para este fin mutualista desinteresado, lo que justifica la prohibición de lo retorno de los excedentes y hace más intenso el principio de la devolución desinteresada.

PALABRAS CLAVE: Cooperativa de solidaridad social, fin mutualista, interés general, miembros de pleno derecho, miembros honorarios, voto plural, retorno de excedentes.

CLAVES ECONLIT: K20, P13, I30.

Cómo citar este artículo/How to cite this article: MEIRA, D.: "0 fim mutualístico desinteressado ou altruísta das cooperativas de solidariedade social", CIRIEC-España, Revista Jurídica de Economía Social y Cooperativa, n³ 36, 2020, pp. 221-247. D0I: 10.7203/CIRIEC-JUR.36.17386. 


\section{THE DISINTERESTED OR ALTRUISTIC MUTUAL PURPOSE OF SOCIAL SOLIDARITY COOPERATIVES}

\section{EXPANDED ABSTRACT}

Social solidarity cooperatives are entities that use work as an instrument to support social inclusion, promoting sheltered employment or therapeutic and occupational activities, to allow active participation of people in the labour market.

This pandemic outbreak of COVID 19 and the resulting economic and social crisis demands from this cooperative branch a significant intervention in providing social services both to its members and to the community where it operates.

This article aims to analyze, at a strictly legal level, the challenges the branch of social solidarity cooperatives face, taking into account the specificities of their object and purpose.

The Portuguese social solidarity cooperatives are integrated into a movement to reinvent the cooperative model started in Italy in 1990 with social cooperatives. This movement led to the emergence of cooperatives with an objective focused mainly or exclusively on the pursuit of objectives of general interest.

One of the main reasons pointed out for the emergence of these particular cooperatives, with an objective focused mainly or exclusively on pursuing the general interest, was the inadequacy of conventional cooperatives to accommodate innovative business phenomena characterized by an objective of collective interest, the absence of a profit aim and a model of organization based on democratic and participatory principles.

This movement has brought with it significant changes in the scope configuration of cooperatives. It does not have to be "exclusively mutualist," it can be " mainly mutualist." It does not have only to pursue directly, but may, exceptionally and providing certain conditions, pursue indirectly. It does not have to respond mainly to the cooperators' interests and may respond mainly to the interests of the community.

Therefore, the mutual purpose of cooperatives is not only to satisfy the needs of their members (interested or egoistic mutual purpose) but also to respond to the interests of the community where the cooperative operates (disinterested or altruistic mutual purpose). 
The legal regime of social solidarity cooperatives sets out in Decree-Law No. 7/98, of 15 January 1998.

From the legal notion, it results that these cooperatives pursue, mainly or exclusively, a disinterested or altruistic mutual purpose, which the legislator calls "social solidarity purposes," which fulfils a clear mission of attending to situations of social and economic vulnerability, based on a paradigm of social intervention, giving expression to the values of altruism and solidarity, contributing to the implementation of social rights.

Since they base all their activity on the values of solidarity and altruism, the legal regime of social solidarity cooperatives has specific characteristics, both concerning the categories of members, the corporate structure, and the economic regime.

These cooperatives are characterized by a heterogeneous membership, which the legislator has grouped into two categories: full members and honorary members.

In light of the current regime, the full members present themselves as the cooperative's reference members. The notion of social solidarity cooperative, contained in Decree-Law 7/98, reports to them. In the light of this notion, the social solidarity cooperative establishes the fulfillment of the social needs of its cooperator members or their families in health, education, professional integration, or a way to develop a professional activity.

The honorary member's category includes all those who contribute with goods or services, particularly social volunteering, to the pursuit of the cooperative's purpose".

Considering that the Cooperative Code has applied subsidiarity to social solidarity cooperatives, we may find another category of members in them: the category of investor members. It is necessary to revisit the concepts of full and honorary membership to adapt them to the current context of social solidarity cooperatives, emphasizing the increasingly important role that social volunteering assumes in these entities. There is no reason why a social solidarity cooperative should not be a volunteer promoting organization, in which volunteers will be the reference members of the cooperative and include the category of full members. The honorary member concept should cover both investor members (since 2015 Cooperative Code reform) and social investors, who are increasingly crucial promoting and sustaining social solidarity cooperatives.

A legal amendment is also needed to remove the restrictions on the full participation of honorary members in general meetings of social solidarity cooperatives. Due to their increasing importance in these cooperatives, honorary members should have the right to vote and be 
elected to the cooperative's governing bodies, being the only way to fulfill the cooperative principle of democratic member control.

In order to combine the interests of these different categories of members, it is necessary to allow a plural vote in social solidarity cooperatives, removing the restrictions provided in the Cooperative Code. Indeed, a plural vote is not allowed in the current state of Portuguese cooperative legislation in social solidarity cooperatives.

As far as the economic regime is concerned, in social solidarity cooperatives, the patronage refund is forbidden, which means that all surpluses must revert to reserves. This impossibility of distributing surpluses results from the fact that these cooperatives carry out their activity mainly in the community's interest, i.e., pursuing a disinterested or altruistic mutual purpose.

The legal regime of surpluses and their return to cooperators bases on the assumption of a cooperative that pursues, mainly or exclusively, an interested or egoistic mutual purpose. The surpluses are the positive results that arise from the cooperative's pursuit of the mutual scope, corresponding to the excess of revenues over costs of the cooperative transactions. This amount is provisionally overpaid by cooperators to cooperatives or underpaid by cooperatives to cooperators, in exchange for their cooperative transactions participation.

We should note that this forbidden of patronage refund implies that the voluntary reserves created with the remaining net annual surpluses will, in no case, be divisible among members. Therefore, when the cooperator leaves the social solidarity cooperative, he will not be entitled to the share of the voluntary divisible reserves.

This disinterested or altruistic mutual purpose implies that the principle of disinterested distribution is more intense in social solidarity cooperatives. In effect, in the event of liquidation of a social solidarity cooperative, which is not succeeded by another cooperative entity of the same branch, the balance of all reserves (mandatory or voluntary) reverts to another social solidarity cooperative, preferably from the same municipality, to be determined by the federation or confederation representing the main activity of the cooperative.

KEYWORDS: Social solidarity cooperatives, mutualistic purpose, general interest, full members, honorary members, plural vote, patronage refund. 


\section{SUMÁRIO}

1. Introdução. 2. 0 problema. 3. A questão da essencialidade do fim mutualístico nas cooperativas. 4. A prevalência do fim mutualístico desinteressado ou altruísta nas cooperativas de solidariedade social. 5. Projeções do fim mutualístico desinteressado ou altruísta no regime jurídico das cooperativas de solidariedade social 5.1. Categorias de membros. 5.2. A admissão dos membros. 5.3. A estrutura orgânica: algumas questões. 5.4. Especificidades do regime económico decorrentes do fim mutualístico desinteressado ou altruísta das cooperativas de solidariedade social. 6 . Conclusões. Bibliografia.

\section{Introdução}

$\mathrm{O}$ texto que se segue teve a sua génese a intervenção apresentada no III Encuentro Internacional de Investigadores sobre Economía Social, Autogestión y Empleo (2019), centrada na inserção sócio laboral de coletivos vulneráveis nas entidades da economia social em Portugal, com especial referência às cooperativas de solidariedade social.

A inserção pelo trabalho representa uma das dimensões do processo mais global de inserção social. As situaçóes de não emprego, de precariedade, de subemprego afastam progressivamente o indivíduo de um trabalho estável e dos respetivos sistemas de proteção social.

As entidades da economia social, tendo em conta as especificidades da atividade que desenvolvem e os princípios que as orientam, estão especialmente vocacionadas para a inserção e para a promoção do trabalho digno e inclusivo.

Nos termos do art. 2. ${ }^{\circ}$, n. ${ }^{\circ} 1$ da Lei de Bases da Economia Social (LBES ${ }^{1}$ ) "entende-se por economia social o conjunto das atividades económico-sociais", livremente levadas a cabo por entidades referidas no art. 4. ${ }^{\circ}$ (associaçóes, cooperativas; fundaçóes, instituiçóes particulares de solidariedade social), atividades estas que "têm por finalidade prosseguir o interesse geral da sociedade, quer diretamente quer através da prossecução dos interesses dos seus membros, utilizadores e beneficiários, quando socialmente relevantes". Por sua vez, o art 5. ' da LBES dispóe que: (...) as entidades da Economia Social são autónomas e atuam no âmbito das suas atividades de acordo com os seguintes princípios orientadores: a) o primado da pessoa e dos objetivos 
sociais; b) a adesão e participação livre e voluntária; c) o controle democrático dos respetivos órgãos pelos seus membros; d) a conciliação entre o interesse dos membros, utilizadores ou beneficiários e o interesse geral; e) o respeito pelos valores da solidariedade, da igualdade e não discriminação, da coesão social, da justiça e da equidade, da transparência, da responsabilidade individual e social partilhada e da subsidiariedade; f) a gestão autónoma e independente das autoridades públicas e de quaisquer outras entidades exteriores à Economia Social; g) a afetação dos excedentes à prossecução dos fins das entidades da Economia Social de acordo com o interesse geral, sem prejuízo do respeito pela especificidade da distribuição dos excedentes, própria da natureza e do substrato de cada entidade da Economia Social, constitucionalmente consagrada .

O destaque dado naquela intervenção ao regime jurídico das cooperativas de solidariedade social deve-se ao facto de estas serem entidades que utilizam o trabalho como um instrumento de apoio à inclusão social, promovendo emprego protegido ou atividades terapêuticas e ocupacionais, de forma a permitir uma efetiva participação das pessoas no mercado de trabalho.

Entretanto, de uma forma súbita e imprevista, abateu-se sobre o mundo o surto pandémico da COVID-19, com graves efeitos sobre a saúde, a economia e o emprego, efeitos estes que atingem sobretudo os grupos mais vulneráveis. Este surto pandémico e a crise económico-social dele decorrente exige deste ramo cooperativo, que tem como objetivo e vocação prioritária o combate à pobreza e à exclusão social, uma maior intervenção na prestação de serviços sociais quer aos seus membros quer à comunidade onde opera. A açáo de solidariedade social exercida por este ramo cooperativo tem dado resposta a situaçóes de emergência social e prestado apoio a indivíduos em situação de maior vulnerabilidade.

Neste contexto, o presente texto pretende analisar, no plano estritamente jurídico, os desafios com que este ramo do setor cooperativo se confronta, tendo em conta as especificidades do seu objeto e fim.

\section{O problema}

No objeto social de toda e qualquer cooperativa articulam-se, numa ótica de complementaridade, duas dimensóes: a económica e a social. Já em 1935, George Fauquet, na sua obra «O setor cooperativo. Ensaio sobre o lugar do Homem nas instituiçóes cooperativas e destas na economia», realçava esta dupla vertente da cooperativa, afirmando que «deve distinguir-se na instituição cooperativa um elemento social e outro económico, visto ser: 1- uma associação de pessoas que reconhecem 
por um lado a similitude de certas necessidades e, por outro lado, a possibilidade de as satisfazer melhor através de uma empresa comum do que individualmente; 2 . $\mathrm{E}$ uma empresa comum cujo objetivo particular responde precisamente às necessidades a satisfazer $\nu^{2}$.

Contudo, nas cooperativas de solidariedade social, a conciliação do interesse dos membros e do interesse geral é mais intensa. As cooperativas de solidariedade social, reguladas pelo Decreto-Lei n. ${ }^{\circ} 78 / 98$, de 15 de janeiro, são cooperativas cujas atividades estâo claramente concentradas na área dos serviços sociais. $\mathrm{O}$ seu objeto social concretiza-se numa clara missão de apoio a situações de vulnerabilidade económica e social, assentando num paradigma assistencialista de intervenção social junto de famílias, crianças, jovens, terceira idade, deficientes, desempregados e outras categorias vulneráveis, com vista à sua integração profissional, educação, formação, atendimento ocupacional e residencial ${ }^{3}$.

Estas cooperativas de solidariedade social inserem-se num movimento de reinvenção do modelo cooperativo iniciado em Itália, em 1990, com as cooperativas sociais italianas ${ }^{4}$. Outros modelos similares emergiram pela Europa, como as cooperativas de iniciativa social espanholas de $1990^{5}$ ou as société coopérative d'intérêt collectiffrancesas $^{6}$.

Uma das principais razóes apontadas para o surgimento destas cooperativas especiais, com um objetivo centrado predominantemente ou exclusivamente na prossecução do interesse geral, foi a inadequaçáo das cooperativas convencionais para acomodar fenómenos empresariais inovadores caracterizados por um objetivo de interesse coletivo, pela ausência de fim lucrativo e por um modo de organizaçáo baseado em princípios democráticos e participativos ${ }^{7}$.

2. V. FAUQUET, G.: O Sector Cooperativo. Ensaio sobre o lugar do homem nas instituiçöes cooperativas e destas na economia (tradução de F. Pinto), Livros Horizonte, Lisboa, 1980, p. 26.

3. V. MEIRA, D.: "The Portuguese Social Solidarity Cooperative versus The PECOL General Interest Cooperative”, International Journal of Cooperative Law, n. ${ }^{\circ}$ 2, 2019, pp. 57-71.

4. V. THOMAS, A.: "The Rise of Social Cooperatives in Italy", Voluntas: International Journal of Voluntary and Nonprofit Organizations, n. ${ }^{\circ}$ 15(3), 2004, pp 243-263.

5. V. RODRÍGUEZ, A. \& ORTEGA, A.: "Algunas consideraciones sobre las cooperativas de iniciativa social en el marco del fomento de empleo y la inserción laboral. una perspectiva jurídico-económica", CIRIEC-España, Revista Jurídica de Economía Social y Cooperativa, n. ${ }^{o}$ 19, 2008, pp. 57-78.

6. V. MARGADO, A.: "SCIC, Société coopérative d'intérêt collectif”, RECMA-Revue Internationale de l'économie sociale, n. ${ }^{\circ}$ 284, 2002, pp. 19-30.

7. V. HIEZ, D.: "The general interest cooperatives: a challenge for cooperative law", IJCL-International Jounal of Cooperative Law, n. ${ }^{\circ}$ I, 2018, pp. 93-109. 
Este movimento trouxe consigo mudanças significativas na configuração do escopo/fim das cooperativas. Este não tem de ser "exclusivamente mutualista", podendo ser "predominantemente mutualista". Não tem de ser prosseguido apenas de forma direta, podendo, excecionalmente, e desde que preenchidas determinadas condiçôes, ser prosseguido indiretamente. Não tem de responder predominantemente aos interesses dos cooperadores, podendo responder predominantemente aos interesses da comunidade ${ }^{8}$.

A análise que se segue pretende responder especificamente às seguintes questóes: (i) será admissível, à luz do quadro jurídico atual, as cooperativas de solidariedade social terem por fim predominante ou exclusivo a satisfação dos interesses da comunidade e não os interesses dos membros? (ii) os interesses dos membros podem traduzir-se diretamente na prossecução dos interesses da comunidade, com base nos valores do altruísmo e da solidariedade? (iii) apresentar-se-á o quadro legal em vigor adequado à prossecução do objeto e fins das cooperativas de solidariedade social?

\section{A questáo da essencialidade do fim mutualítico nas cooperativas}

As cooperativas são «pessoas coletivas autónomas, de livre constituição, de capital e composição variáveis, que, através da cooperação e entreajuda dos seus membros, com obediência aos princípios cooperativos, visam, sem fins lucrativos, a satisfação das necessidades e aspiraçóes económicas, sociais ou culturais daqueles» (n. ${ }^{\circ} 1$ do art. 2. ${ }^{\circ}$ do Código Cooperativo português (CCoop) ${ }^{9}$.

O fim da cooperativa surge intimamente ligado à promoção dos interesses dos cooperadores, ou seja, à satisfação das suas necessidades económicas, sociais e culturais. As cooperativas não têm um fim próprio ou autónomo face aos seus membros, sendo um instrumento de satisfação das necessidades individuais (de todos e de cada um) dos cooperadores, que, no seio dela, e através dela trabalham, consomem, vendem e prestam serviços ${ }^{10}$.

8. MEIRA, D.: "O princípio da participação económica dos membros à luz dos novos perfis do escopo mutualístico", Boletín de la Asociación de Derecho Cooperativo, n. ${ }^{\circ}$ 53, 2018, pp. 107-137.

9. Lei n. ${ }^{\circ}$ 119/2015, de 31 de agosto, com as alteraçóes constantes da Lei n. ${ }^{\circ}$ 66/2017, de 9 de agosto.

10. FICI, A.: "Chapter 1- Definition and Objectives of Cooperatives. Commentary". In Principles of European Cooperative Law. Principles, Commentaries and National Reports (FAJARDO, G., FICI, A., HENRŸ, H., HIEZ, D., MEIRA, D., MÜNKNER, D., \& SNAITH, I.), Intersentia, Cambridge, 2017, pp. 27 e ss. 
O fim da cooperativa não é, por isso, a obtenção de lucros para depois os repartir, mas maximizar a vantagem que os membros retiram das operaçôes que realizam com a cooperativa ou através da cooperativa.

A instrumentalidade da cooperativa face aos membros resulta, então, do facto de a atividade da cooperativa se orientar necessariamente para os seus membros, que são os destinatários principais das atividades económicas e sociais que esta leva a cabo. Diz-se, por isso, que as cooperativas têm um escopo mutualístico.

$\mathrm{Na}$ decorrência do escopo mutualístico da cooperativa, os cooperadores assumem a obrigaçáo de participar na atividade da cooperativa, cooperando mutuamente e entreajudando-se. As cooperativas operam com os seus membros, no âmbito de uma atividade que a eles se dirige e na qual participam (al. c) do n. ${ }^{\circ} 2$ do art. $22 .^{\circ}$ do CCoop). Esta participação, assente na cooperação e entreajuda, traduzir-se-á num intercâmbio recíproco de prestaçóes entre a cooperativa e os cooperadores, prestaçóes essas que são próprias do objeto social da cooperativa.

A fórmula legal do art. $2 .^{\circ}$ do CCoop permite-nos, então, concluir que a cooperativa é uma entidade composta por três ou mais sujeitos (os cooperadores) para o exercício de uma atividade económica na qual os cooperadores participam cooperando (objeto social), a fim de satisfazer as necessidades daqueles (fim ou escopo mutualístico).

O fim mutualístico terá, deste modo, um caráter essencial na cooperativa. No entanto, torna-se necessário adotar um conceito de fim mutualístico aberto, suscetível de abranger as especificidades do regime jurídico das cooperativas de todos os ramos.

Efetivamente, à dimensão económica do objeto das cooperativas junta-se uma dimensão social.

Neste sentido, o princípio do interesse pela comunidade, que aparece enunciado no art. $3 .^{\circ}$ do CCoop, dispóe que «as cooperativas trabalham para o desenvolvimento sustentável das suas comunidades, através de políticas aprovadas pelos membros».

Assim, ainda que centradas nas necessidades dos seus membros, as cooperativas trabalham para conseguir o desenvolvimento sustentável das suas comunidades, segundo os critérios aprovados pelos membros.

Este princípio apresenta uma forte conexão com um outro princípio cooperativo, o princípio da adesão voluntária e livre, que corresponde ao tradicional princípio da porta aberta e que aparece formulado também no art. 3. ${ }^{\circ}$ do CCoop nos seguintes termos: «As cooperativas são organizaçóes voluntárias, abertas a todas as pessoas aptas a utilizar os seus serviços e dispostas a assumir a responsabilidade de membro, sem discriminaçôes de sexo, sociais, políticas, raciais ou religiosas». Este princípio poderá ser encarado através de duas perspetivas, a saber: em primeiro lugar, a adesão deverá ser voluntária, uma vez que dependerá, exclusivamente, da vontade do cooperador; 
em segundo lugar, a adesão deverá ser aberta a todas as pessoas, desde que estas, como candidatas a cooperadores, preencham duas condiçóes: a possibilidade de fruírem da utilidade própria da cooperativa; e a aceitação das responsabilidades inerentes à filiação.

Esta conexão entre os dois princípios é evidente, uma vez que a permeabilidade que acompanhou tradicionalmente a cooperativa no momento de incorporar novos membros encontra a sua justificação na vontade de serviço à comunidade em que aquela está inserida. A incorporação de membros provenientes do âmbito territorial onde a cooperativa realiza maioritariamente a sua atividade foi uma constante neste tipo organizacional, cuja finalidade última seria a da satisfação das necessidades sentidas pela comunidade, aparecendo a cooperativa, deste modo, como entidade geradora de empregos estáveis (principalmente porque as cooperativas, em virtude do seu forte enraizamento a nível local, desenvolvem atividades que, pela sua própria natureza, não são suscetíveis de serem deslocalizáveis) e fomentadora de um espírito empreendedor.

Assim, as cooperativas terão a particular responsabilidade de assegurar que o desenvolvimento das suas comunidades seja económica, social e culturalmente sustentado.

Destes princípios decorrerá, portanto, o envolvimento das cooperativas no contexto social, cabendo aos cooperadores a escolha das políticas através das quais esse envolvimento se concretizará.

Um outro princípio de enorme relevância para a sustentação da afirmação de que o objeto da cooperativa abrange o desenvolvimento de atividades com uma dimensão social relevante será o princípio da educação, formação e informação (art. 3. ${ }^{\circ}$ do CCoop).

Diz o legislador que «as cooperativas promoverão a educação e a formação dos seus membros, dos representantes eleitos, dos dirigentes e dos trabalhadores, de modo que possam contribuir eficazmente para o desenvolvimento das suas cooperativas. Elas devem informar o grande público, particularmente os jovens e os líderes de opiniáo, sobre a natureza e as vantagens da cooperação» (art. 3. ${ }^{\circ}$ do CCoop).

Este princípio realça a obrigação de as cooperativas, na sua atividade, assegurarem a educação e formação, quer dos seus membros, quer dos titulares dos seus órgãos eleitos, quer dos seus administradores, quer dos seus trabalhadores.

Além disso, este princípio abrange o dever de informar o público em geral, visando sensibilizá-los para a natureza e benefícios da cooperação, o que poderá fomentar novas adesóes, e sobretudo adesóes conscientes.

Refira-se, finalmente, que este princípio se concretiza, no Código Cooperativo português, através da consagração de uma reserva obrigatória "para a educação coo- 
perativa e a formação cultural e técnica dos cooperadores, dos trabalhadores da cooperativa e da comunidade» (art. 97. ${ }^{\circ}$ ). Esta reserva constitui uma das notas mais distintivas da empresa cooperativa relativamente às restantes formas de empresa. Cria-se um património afetado a fins sociais, do qual beneficiarão os próprios cooperadores, os trabalhadores da cooperativa e o meio social ${ }^{11}$.

A constituição deste tipo de reserva, com esta finalidade, significa que a cooperativa é não só uma organização económica, mas também uma organização com finalidades sociais ${ }^{12}$.

Poderemos, assim, afirmar que o fim mutualístico das cooperativas não se circunscreve à satisfação das necessidades dos seus membros (fim mutualístico interessado ou egoísta), devendo atender, igualmente, aos interesses da comunidade onde a cooperativa desenvolve a sua atividade (fim mutualístico desinteressado ou altruísta) ${ }^{13}$.

\section{A prevalência do fim mutualístico desnteressado ou altruísta nas cooperativas de solidariedade social}

O regime jurídico das cooperativas de solidariedade social consta de um diploma próprio, o Decreto-Lei n. ${ }^{\circ}$ 7/98, de 15 de janeiro.

No preâmbulo deste Decreto-Lei afirma-se que o legislador ao instituir o ramo das cooperativas de solidariedade social "criou mais um instrumento a que a sociedade civil poderá recorrer no combate à pobreza e à exclusão social", acrescentando-se que a «solidariedade exerce-se assim em muitas áreas que encontram resposta privilegiada na generosidade, voluntariado e intervenção muito própria do setor cooperativo».

11. V. MEIRA, D.A.: "Reflexōes em torno do regime jurídico da reserva de educação e formação cooperativas". In O Pensamento Feminino na Construção do Direito Cooperativo (Coord. TEIXEIRA, M. FERRAZ \& TEIXEIRA), Vincere Editora, Brasília, 2017, pp. 57-72.

12. FICI, A.: "La funzione sociale delle cooperative: note di diritto comparato". In Verso un Diritto Dell" Economia Sociale. Teoria. Tendenze e Prospettive Italiane ed Europee, Editoriale Scienttifica, Napoli, 2016, pp. 241- 263.

13. Nesta divisão do fim mutualístico em fim interessado ou egoístico e fim desinteressado ou altruísta, tomamos por referência, em termos de terminologia, a classificaçấo das pessoas coletivas adotada, entre outros autores portugueses, por ANDRADE, M.: Teoria Geral da Relação Jurídica, vol. I - Sujeitos e Objecto, Coimbra Editora, Coimbra, pp. 77 e ss.. De acordo com essa classificação, as pessoas coletivas de Direito Privado dividem-se em: (i) pessoas coletivas de utilidade pública - de fim desinteressado ou altruístico; (ii) pessoas coletivas de fim interessado ou egoístico, as quais se subdividem em pessoas de fim ideal ou pessoas coletivas de fim económico não lucrativo e pessoas coletivas de utilidade particular ou fim económico lucrativo. 
Quanto ao direito que lhes é aplicável, o art. $10^{\circ}$ deste diploma dispóe que as cooperativas de solidariedade social se regem «pelo regime previsto neste diploma e, nas suas omissões, pelas do Código Cooperativo».

Temos, portanto, que nas áreas não cobertas pela regulação constante do Decreto-Lei n. ${ }^{\circ}$ 7/98, de 15 de janeiro, aplicar-se-âo, de modo direto, as normas mais gerais do Código Cooperativo, que menciona o ramo das cooperativas de solidariedade social na al. l) do n. ${ }^{\circ} 1$ do art. $4 .^{\circ}$. Por sua vez, o n. ${ }^{\circ} 4$ deste mesmo artigo dispóe que "As cooperativas de solidariedade social que prossigam os objetivos previstos no artigo $10^{\circ}$ do Estatuto das Instituiçóes Particulares de Solidariedade Social, aprovado pelo DL n. ${ }^{\circ} 119 / 83$, de 25 de fevereiro, com a redação dada pelo DL n. ${ }^{\circ}$ 172-A/2014, de 14 de novembro, e que sejam reconhecidas nessa qualidade pela Direção-Geral da Ação Social, são equiparadas às instituições particulares de solidariedade social, aplicando-se-lhes o mesmo estatuto de direitos, deveres e benefícios, designadamente fiscais» ${ }^{14}$.

Prevê-se, deste modo, uma equiparação das cooperativas de solidariedade social às instituições particulares de solidariedade social (IPSS), aplicando-se-lhes o mesmo estatuto de direitos, deveres e benefícios previsto no mencionado Estatuto das Instituiçôes Particulares de Solidariedade Social (EIPSS). O reconhecimento por equiparação a IPSS das cooperativas de solidariedade social que prossigam os objetivos previstos no Estatuto das IPSS obedecerá às regras previstas no Despacho n. ${ }^{\circ}$ 3859/2016 do Ministério do Trabalho, Solidariedade e Segurança Social. Nos termos do referido diploma (art. 1. ${ }^{\circ}$ ), tal reconhecimento poderá ser requerido pela própria cooperativa à Direção-Geral da Segurança Social (DGSS), devidamente instruído (art. 2. ${ }^{\circ}$ ), seguindo-se a emissão de um parecer fundamentado quanto ao pedido por parte do Centro Distrital da Segurança Social da área da sede da cooperativa (art. 3. ${ }^{\circ}$ ). Posteriormente, o processo seguirá para a DGSS, que, após avaliação, proferirá despacho de concessão ou recusa do reconhecimento (art. 4.o $)^{15}$.

Existe, assim, uma pluralidade de diplomas-fonte de regulação das cooperativas de solidariedade social, que se regem pelo o regime previsto no Decreto-Lei n.o 7/98, de 15 de janeiro e, nas suas omissóes, pelas do Código Cooperativo, sem prejuízo da extensão às cooperativas de solidariedade social dos direitos, deveres e benefícios das IPSS, contantes do EIPSS.

14. V. FERNANDES, T.: "Artigo 4. "." In: Código Cooperativo Anotado (Coord. MEIRA, D. \& RAMOS, M.E.), Almedina, Coimbra, 2018, pp. 37-42.

15. V. SARAIVA, R.: "As instituiçóes particulares de solidariedade social". In Organização Administrativa: novos actores, novos modelos (Coord. GOMES, C.A., NEVES, A.F. \& TIAGO SERRĀO), Vol. II. Lisboa: AAFDL Editora, Lisboa, pp. 69-97. 
$\mathrm{O}$ art. $2 .^{\circ}$ do Decreto-Lei n. ${ }^{\circ} 7 / 98$, de 15 de janeiro fornece a noção de cooperativas de solidariedade social: «1 - São cooperativas de solidariedade social as que através da cooperação e entreajuda dos seus membros, em obediência aos princípios cooperativos, visem, sem fins lucrativos, a satisfação das respetivas necessidades sociais e a sua promoção e integração, nomeadamente nos seguintes domínios: a) Apoio a grupos vulneráveis, em especial a crianças e jovens, pessoas com deficiência e idosos; b) Apoio a famílias e comunidades socialmente desfavorecidas com vista à melhoria da sua qualidade de vida e inserção socioeconómica; c) Apoio a cidadãos portugueses residentes no estrangeiro, durante a sua permanência fora do território nacional e após o seu regresso, em situação de carência económica; d) Desenvolvimento de programas de apoio direcionados para grupos alvo, designadamente em situaçóes de doença, velhice, deficiência e carências económicas graves; e) Promoção do acesso à educação, formação e integração profissional de grupos socialmente desfavorecidos. 2 - Além dos enumerados no número anterior, as cooperativas de solidariedade social podem desenvolver outras açóes que apresentem uma identidade de objeto com as previstas no número anterior e, nos limites do Código Cooperativo, prestar serviços a terceiros».

Esta noção legal torna evidente que não se permite uma cooperativa de solidariedade social sem um escopo mutualístico mínimo. Nas palavras do legislador, estas cooperativas «mediante a cooperação e a entreajuda dos seus membros e em obediência aos princípios cooperativos, visam, sem fins lucrativos, a satisfação das respetivas necessidades sociais e a sua promoção e integração".

A noção legal também torna evidente que o objetivo das cooperativas de solidariedade social se concretiza numa clara missão de assistência a situações de vulnerabilidade social e económica, assentando num paradigma de intervenção social, dando expressão aos valores do altruísmo e da solidariedade, contribuindo para a efetivação dos direitos sociais.

As especificidades deste objetivo são reforçadas pelo facto de, como vimos, serem equiparadas a IPSS as cooperativas de solidariedade social que prossigam os objetivos previstos no art. 1. ${ }^{\circ}-\mathrm{A}$ do Estatuto das IPSS. Ora, tais objetivos concretizam -se mediante a concessão de bens, prestação de serviços e de outras iniciativas de promoção do bem -estar e qualidade de vida das pessoas, famílias e comunidades, nomeadamente nos seguintes domínios: a) Apoio à infância e juventude, incluindo as crianças e jovens em perigo; b) Apoio à família; c) Apoio às pessoas idosas; d) Apoio às pessoas com deficiência e incapacidade; e) Apoio à integração social e comunitária; f) Proteção social dos cidadãos nas eventualidades da doença, velhice, invalidez e morte, bem como em todas as situaçôes de falta ou diminuição de meios de subsistência ou de capacidade para o trabalho; g) Prevenção, promoção e proteção 
da saúde, nomeadamente através da prestação de cuidados de medicina preventiva, curativa e de reabilitação e assistência medicamentosa; h) Educação e formação profissional dos cidadãos; i) Resolução dos problemas habitacionais das populações; $\mathbf{j}$ ) Outras respostas sociais não incluídas nas alíneas anteriores, desde que contribuam para a efetivação dos direitos sociais dos cidadãos ${ }^{16}$.

Torna-se assim evidente que, nas cooperativas de solidariedade social, a força motriz não é a prossecução de um fim mutualístico interessado ou egoísta, mas a prossecução de um fim mutualístico desinteressado, assente nos valores do altruísmo e da solidariedade.

Este fim desinteressado ou altruísta, que o art. 9. ${ }^{\circ}$ do Decreto-Lei n. ${ }^{\circ} 7 / 98$, de 15 de janeiro designa de "fins de solidariedade social», tem de ser confirmado pela credencial emitida pela Cooperativa António Sérgio para a Economia Social (CASES). Efetivamente, o referido art. $90^{\circ}$ sujeita as cooperativas de solidariedade social à credenciação prevista no art. $117 .^{\circ}$ do CCoop, que, além de confirmar a natureza cooperativa da entidade constituída e o seu legal funcionamento, confirmará também os seus fins de solidariedade social, sendo que o apoio técnico e financeiro por parte das entidades públicas, nomeadamente nas áreas da inserção e segurança social, fica dependente daquela credencial ${ }^{17}$.

\section{Projeçóes do fim mutualístico desinteressado ou altruísta no regime jurídico das cooperativas de solidariedade social}

As cooperativas de solidariedade social baseiam toda a sua atividade nos valores da solidariedade e do altruísmo, pelo que o seu regime jurídico apresenta certas peculiaridades, quer no que respeita às categorias de membros, quer quanto à estrutura orgânica, quer quanto ao regime económico.

Nas linhas que se seguem pretendemos identificar estas especificidades e averiguar se as mesmas estão adequadamente tratadas na legislação que enquadra as cooperativas de solidariedade social.

16. V. LOPES, L.: "Breves nótulas sobre o "novo estatuto" das Instituiçôes Particulares de Solidariedade Social no Direito nacional e no Direito da Uniáo Europeia”, Cooperativismo e Economia Social, n. o 37, 2018, pp. 139-164.

17. V. OLIM, A.C.: "Artigo 117.o". In Código Cooperativo Anotado (Coord. MEIRA, D. \& RAMOS, M.E.), Almedina, Coimbra, 2018, pp. 621-623. 


\subsection{Categorias de membros}

À luz do disposto nos arts. 4. ${ }^{\circ}$ e 5. ${ }^{\circ}$ do Decreto-Lei n. ${ }^{\circ} 7 / 98$, de 15 de janeiro, os membros das cooperativas de solidariedade social podem ser de duas categorias: membros efetivos e membros honorários.

$\mathrm{O}$ art. $4 .^{\circ}$ dispóe que "podem ser membros efetivos as pessoas que, propondo-se utilizar os serviços prestados pela cooperativa, em benefício próprio ou dos seus familiares, ou nela desenvolver a sua atividade profissional, voluntariamente solicitem a sua admissão».

Por sua vez, o art. $5 .^{\circ}$ dispóe, no seu n. ${ }^{\circ} 1$, que «Podem ser membros honorários aqueles que contribuam com bens ou serviços, nomeadamente de voluntariado social, para o desenvolvimento do objeto da cooperativa».

A cooperativa de solidariedade social pode, assim, funcionar: (i) como uma cooperativa de utentes, quando os seus membros sáo os beneficiários principais dos bens ou dos serviços por ela disponibilizados; (ii) como uma cooperativa de produtores, quando associa pessoas que nela visam desenvolver a sua atividade profissional ou de voluntariado social; (ii) ou como uma cooperativa mista de utentes e produtores.

À luz do atual regime, os membros efetivos apresentam-se como os membros de referência da cooperativa. A eles se reporta a noção de cooperativa de solidariedade social constante do art. 2. ${ }^{\circ}$ do Decreto-Lei n. ${ }^{\circ} 7 / 98$, de 15 de janeiro. Como já foi referido, a cooperativa de solidariedade social nasce para satisfazer as necessidades sociais dos seus membros cooperadores ou das suas famílias nos domínios da saúde, da educação, da integraçáo profissional, ou como via para o desenvolvimento de uma atividade profissional.

$\mathrm{Na}$ categoria dos membros honorários, o legislador destaca os membros voluntários, os quais assumem uma cada vez maior importância nas cooperativas de solidariedade social.

O voluntário é o «indivíduo que de forma livre, desinteressada e responsável se compromete, de acordo com as suas aptidóes próprias e no seu tempo livre, a realizar ações de voluntariado no âmbito de uma organização promotora» (art. $3^{\circ}$, no 1 , da Lei n. ${ }^{\circ} 71 / 98$, de 3 de novembro). A qualidade de voluntário náo pode decorrer de relação de trabalho subordinado ou autónomo ou de qualquer relação de conteúdo patrimonial com a organização promotora, sem prejuízo de regimes especiais constantes da lei.

A este propósito cabe perguntar se pode ou não uma cooperativa de solidariedade social funcionar como uma organização promotora de voluntariado.

Podem ser organizaçóes promotoras de voluntariado as organizaçóes públicas da administração central, regional ou local ou outras pessoas coletivas de direito público 
ou privado, legalmente constituídas, que reúnam condiçóes para integrar voluntários e coordenar o exercício da sua atividade (Lei n. ${ }^{\circ} 71 / 98$, de 3 de novembro). Por sua vez, o Decreto-Lei n. ${ }^{\circ}$ 389/99, de 30 de setembro estabelece que são organizaçóes promotoras de voluntariado as que reúnem condiçóes para integrar voluntários e coordenar o exercício da sua atividade, desenvolvendo atividades nos seguintes domínios: cívico, da ação social, da saúde, da educação, da ciência e cultura, da defesa do património e do ambiente, da defesa do consumidor, da cooperaçâo para o desenvolvimento, do emprego e da formação profissional, da reinserção social, da proteção civil, do desenvolvimento da vida associativa e da economia social, da promoçáo do voluntariado e da solidariedade social, ou em outros de natureza análoga ${ }^{18}$.

Nada impede que a forma jurídica escolhida para enquadrar uma organização promotora de voluntariado seja a cooperativa de solidariedade social, existindo já em Portugal alguns exemplos de cooperativas de solidariedade social promotoras de voluntariado ${ }^{19}$.

Porque os voluntários podem ser os membros de referência de uma cooperativa de solidariedade social, torna-se necessário revisitar as definiçóes legais de membro efetivo e de membro honorário. Quando um grupo de voluntários constitui uma cooperativa de solidariedade social para através dela, de forma integrada, exercer a sua atividade de voluntariado, à luz das definiçôes em vigor, estaremos perante membros efetivos e não membros honorários. Deveria, por isso, a definição legal de membro efetivo referir, para além do exercício da atividade profissional, o exercício de outras atividades, designadamente a de voluntariado social.

Tendo em conta que o Código Cooperativo se aplica subsidiariamente às cooperativas de solidariedade social, poderemos nelas encontrar uma outra categoria de membros: a categoria dos membros investidores. A figura dos membros investidores constituiu uma das mais relevantes novidades da reforma de 2015 do Có digo Cooperativo Português. Estes membros investidores poderão proporcionar à cooperativa a obtenção de meios de financiamento em melhores condiçôes do que os oferecidos pelo mercado, quando não sejam suficientes os recursos trazidos pelos membros cooperadores (art. 20. ${ }^{\circ}$ do CCoop) ${ }^{20}$.

18. V. FERREIRA, F.: "O voluntariado e a promoçăo do voluntariado em Portugal", Cooperativismo e Economia Social, n.o 36, 2017, pp. 305-316; CATARINO, A.: "Prática do voluntariado. Economia Social na prática”, Revista ES-Economia Social. Leituras e Debates, n.o 2, Agosto 2018, www.revista-es.info.

19. Informação disponível em: https://portugalvoluntario.pt/cs2i/organizations-list?dswid=4326

20. V. FAJARDO, G.: "Artigo 20.o". In Código Cooperativo Anotado (Coord. MEIRA, D. \& RAMOS, M.E.), Almedina, Coimbra, 2018, pp. 122-128. 
A sustentabilidade financeira das cooperativas de solidariedade social passa pela sua capacidade de aumentar as receitas próprias, recorrendo à figura dos membros investidores ou outras.

No entanto, são por todos reconhecidas as dificuldades em mobilizar financiamento público ou privado para as entidades que operam no setor social. Este reconhecimento levou ao surgimento de um novo segmento do setor financeiro, denominado de investimento social, o qual visa promover a sustentabilidade e o crescimento dos projetos de inovação social incubados em organizaçóes do setor da economia social, obtendo o investidor social não um retorno financeiro em sentido estrito, mas um retorno associado à geração de impacto social ou ambiental mensurável ${ }^{21}$. O investimento social surge, assim, associado a práticas de investimento socialmente responsável. Este mercado de investimento social abrange um conjunto de instrumentos financeiros, tais como: a Capacitação para o Investimento Social; as Parcerias para o Impacto; os Títulos de Impacto Social; o Fundo para a Inovação Social; as Obrigaçóes de Impacto Social ${ }^{22}$.

Estes investidores sociais poderão, ainda, assumir a veste de mecenas sociais, os quais concedem donativos em dinheiro ou em espécie, usufruindo, em contrapartida, de um benefício fiscal (art. 2. ${ }^{\circ}$ do Decreto-Lei n. ${ }^{\circ} 74 / 99$ de 16 de março).

Não pode o legislador alhear-se deste novo mercado dos investidores sociais, devendo oferecendo-lhes a possibilidade de uma participação mais ativa na vida da cooperativa, a qual se se poderá concretizar mediante a aquisição da qualidade de membro honorário.

\subsection{A admissáo dos membros}

Refira-se que podem ser membros de uma cooperativa todas as pessoas singulares ou coletivas, de direito público ou privado, que preencham os requisitos de admissão previstos na lei e nos estatutos.

O Decreto-Lei n. ${ }^{\circ} 7 / 98$, de 15 de janeiro é omisso quanto ao processo de admissão dos membros efetivos, pelo que se aplicarão as disposiçóes do Código Cooperativo, pensadas para as cooperativas em geral e que, portanto, não contemplam eventuais especificidades decorrentes do facto de, nas cooperativas de solidariedade social, o fim prosseguido ser um fim desinteressado ou altruísta.

21. V. ALMEIDA, F. \& SANTOS, F.: "Portugal Inovação Social: na encruzilhada dos tempos”, Cooperativismo e Economia Social, n. ${ }^{\circ}$ 39, 2017, pp. 443-462.

22. V. MEIRA, D. \& RAMOS, M.E.: "Social entrepreneurship: legislative contributions", RED. Revista Eletrónica de Direito, n. 2 (VOL. 19), 2019, pp. 136-162. 
Este regime de admissão, assente no princípio da adesão voluntária e livre, estabelece que o candidato a membro cooperador efetivo deverá requerer a sua admissão junto do órgão de administração da cooperativa (n. ${ }^{\circ} 1$ do art. 19. ${ }^{\circ}$ do CCoop).

O legislador estabeleceu que os estatutos de cada cooperativa deverão conter as "condiçốes de admissão" dos membros [al. a), do n. ${ }^{\circ}$ 2, do art. 16. ${ }^{\circ}$ do CCoop]; e, se um candidato preencher essas condições, a proposta de admissão terá ainda que ser objeto de deliberação do órgão de administração e/ou da assembleia geral [arts. 38. ${ }^{\circ}$, al. k) e $47 .^{\circ}$, al. d), do CCoop]. Esta deliberação terá caráter constitutivo, quanto à aquisição da qualidade de cooperador. A admissão ou a recusa é comunicada ao candidato no prazo fixado nos estatutos, ou supletivamente no prazo máximo de 180 dias (n. ${ }^{\circ}$ do art. $19 .^{\circ}$ do CCoop) ${ }^{23}$.

Não há qualquer imposição legal de que as cooperativas aceitem membros honorários. Não funciona para esta categoria de membros o princípio da adesão voluntária e livre. Assim se compreende que o n. ${ }^{\circ} 2$ do art. $5 .^{\circ}$ do Decreto-Lei n. ${ }^{\circ} 7 / 98$, de 15 de janeiro estabeleça que a admissão dos membros honorários é feita em assembleia geral, mediante proposta fundamentada do órgão de administração da cooperativa, da qual constará obrigatoriamente um relatório sobre as liberalidades em bens ou serviços que contribuam de forma notória para o desenvolvimento do objeto da cooperativa.

Quanto à admissão de membros investidores aplicar-se-ão as disposiçóes previstas no Código Cooperativo.

A admissão de membros investidores resultará sempre de uma decisão dos membros cooperadores. Assim, no momento da constituiçấo da cooperativa de solidariedade social, os estatutos deverão necessariamente fixar as "condiçóes e limites da existência de membros investidores quando os houver» (al. f) do n. ${ }^{\circ} 1$ do art. 16. ${ }^{\circ}$ do CCoop). No n. ${ }^{\circ} 1$ do art. $20 .^{\circ}$ determina-se que «os estatutos podem prever a admissão de membros investidores». Isto significa que os membros investidores não poderão ser membros fundadores da cooperativa.

Para além de previsão estatutária, a admissão de membros investidores ainda estará dependente de proposta do órgão de administração a ser submetida a aprovação da assembleia geral (n. ${ }^{\text {os }} 3$ e 4 do art. 20. ${ }^{\circ}$ do CCoop).

Quando há a participação do Estado ou de pessoas coletivas de direito público, o modelo adotado tem sido o da constituição, por decisão administrativa, de uma cooperativa de interesse público (Decreto-Lei 31/84, de 21 de janeiro e art. 6. ${ }^{\circ}$ do 
CCoop), inserida no ramo da solidariedade social. Estamos perante uma forma cooperativa de prestação de serviços de interesse público, promovendo atividades económicas de relevante interesse geral, sendo os cidadãos os consumidores dos serviços prestados ou produzidos ${ }^{24}$.

\subsection{A estrutura orgânica: algumas questóes}

Os órgãos legais das cooperativas de solidariedade social portuguesas compreendem a assembleia geral, o órgão de administração, os órgãos de fiscalização (n. ${ }^{\circ} 1$ do art. 27. ${ }^{\circ}$ do CCoop) e, ainda, caso os estatutos o prevejam, um "Conselho geral", que reúne todos os membros honorários e todos os titulares dos órgãos sociais $\mathrm{da}$ cooperativa (art. 6. ${ }^{\circ}, \mathrm{n}^{\circ} 1$ do Decreto-Lei n. ${ }^{\circ} 7 / 98$ ).

$\mathrm{Na}$ assembleia geral participam todos os cooperadores e membros investidores no pleno gozo dos seus direitos (art. 33. ${ }^{\circ}$ do CCoop).

A participação em assembleias gerais é um direito/dever dos membros.

O direito de participação plena compreende: o direito de estar presente nas reuniôes, o direito de nelas apresentar propostas, o direito de pedir informaçóes e de intervir nos debates, e o direito de votar (art. $21^{\circ}$, n. $^{\circ} 1$, al. b), do CCoop).

Ora, impóe-se uma alteração do regime jurídico das cooperativas de solidariedade social, dado que este prevê uma restrição à participação plena dos membros honorários na assembleia geral, os quais apenas podem assistir às assembleias gerais sem direito de voto (art. 5. ${ }^{\circ}$, n. 3 do Decreto-Lei n. ${ }^{\circ} 7 / 98$ ), o que viola claramente o princípio cooperativo da gestáo democrática pelos membros (art. 3. ${ }^{\circ}$ do CCoop). Efetivamente, o direito de tomar parte na assembleia geral constitui o "núcleo duro" do direito de participaçáo de um membro numa cooperativa, que é, à luz daquele princípio, uma organização "democraticamente gerida pelos seus membros».

Acresce que também encontramos na legislação setorial das cooperativas de solidariedade social uma compressão do direito de eleger e ser eleito para os órgãos da cooperativa (al. c) do n. ${ }^{\circ} 1$ do art. $21 .^{\circ}$ do CCoop). Este direito enquadra-se no direito mais geral de participar na governação da cooperativa, compreendendo duas dimensôes: uma dimensão ativa (o direito de eleger) e uma dimensão passiva (o direito de ser eleito). Este direito está intimamente ligado ao princípio da autogestáo cooperativa, que, por sua vez, decorre do referido princípio da gestáo democrática ${ }^{25}$.

24. V. LEITE, J.Z.: "Artigo 6.o". In Código Cooperativo Anotado (Coord. MEIRA, D. \& RAMOS, M.E.), Almedina, Coimbra, 2018, pp. 45-51.

25. V. FICI, A.: "Artigo 21.o". In Código Cooperativo Anotado (Coord. MEIRA, D. \& RAMOS, M.E.), Almedina, Coimbra, 2018, pp. 129-134. 
Ora, o n. ${ }^{\circ} 3$ do art. $5 .^{\circ}$ do Decreto-Lei n. ${ }^{\circ} 7 / 98$ impede os membros honorários de elegerem ou serem eleitos para os órgáos sociais da cooperativa de solidariedade social.

Uma outra questão que merece a nossa atenção prende-se com a circunstância de estas cooperativas se caraterizarem, frequentemente, por uma heterogeneidade de membros: membros trabalhadores, membros voluntários, membros destinatários dos serviços prestados pela cooperativa ou seus familiares, membros investidores, membros financiadores, entre outros ${ }^{26}$.

Como conciliar os interesses das diferentes categorias de membros em termos de governação cooperativa? Como assegurar uma governação verdadeiramente participativa e democrática?

Nas cooperativas com diferentes categorias de membros existe uma heterogeneidade que obriga à definição de regras quanto ao exercício do direito de voto e quanto à participação nos órgãos da cooperativa, regras estas que deverão impedir que uma categoria de membros possa dominar as demais. O legislador português resolveu este problema privando os membros honorários do exercício do direito de voto e do exercício do direito de eleger e ser eleito para os órgãos da cooperativa. Contudo, já realçamos que estas disposiçóes legais violam o princípio cooperativo da gestâo democrática pelos membros, pelo que haverá que encontrar outras soluçôes.

A doutrina tem apontado como possíveis soluçôes as seguintes: admissibilidade do voto plural; definição, por via estatutária, de regras que garantam uma representação justa e equitativa de cada categoria de membros nos órgãos de administração e de fiscalização ${ }^{27}$.

Estas regras estão previstas no Código Cooperativo que, desde a reforma de 2015, admite duas categorias de membros (os membros cooperadores, que são os membros de referência da cooperativa, e os membros investidores) e a possibilidade do voto plural.

Efetivamente, os membros investidores podem participar, ainda que limitadamente, nas decisóes da cooperativa, não podendo representar, em caso algum, mais de $25 \%$ do número de elementos efetivos que integrem o órgão (de administração ou de fiscalização) para que são eleitos (n. ${ }^{\circ} 8$ do art. $29 .^{\circ}$ do CCoop).

26. V. HIEZ, D.: "The general interest cooperatives: a challenge for cooperative law", cit., pp. 105-106.

27. V. MÜNKNER, H.: "How co-operative are social co-operatives?", CES -Cooperativismo e Economía Social, n. ${ }^{\circ} 38,2016$, p. 54; SNAITH, I.: "Chapter 2. Cooperative Governance. Commentary". In Principles of European Cooperative Law. Principles, Commentaries and National Reports, cit., pp. 60 e ss. 
Nas assembleias gerais das cooperativas de primeiro grau, a regra é a da igualdade de direito de voto de todos os membros (art. $40 .^{\circ}$ do CCoop) ${ }^{28}$, mas admite-se a possibilidade de os estatutos consagrarem, respeitados que sejam determinados limites legais imperativos, o voto plural nas cooperativas de primeiro grau (n. ${ }^{\circ} 1$ do art. $41 .{ }^{\circ}$ do CCoop), o qual pode ser atribuído a cooperadores ou a membros investidores. Sendo atribuído a cooperadores, sê-lo-á sempre em função da atividade do cooperador na cooperativa (art. 41. ${ }^{\circ}$ do CCoop) e nunca em função da participação no capital social. O Código Cooperativo remete para os estatutos a definição das condições e critérios de que depende a atribuição de voto plural a membros investidores (n. ${ }^{\circ} 5$ do art. 41. ${ }^{\circ}$ do CCoop).

Em nome dos princípios cooperativos da gestão democrática e da autonomia e independência, o Código Cooperativo consagra, em normas legais imperativas, limites quanto à atribuição do voto plural (art. 41. ${ }^{\circ}$ do CCoop): a) limites quanto à dimensão da cooperativa -em cooperativas com menos de 20 cooperadores está proibido o voto plural; b) limites quanto a determinados ramos- o voto plural está proibido nas cooperativas de produção operária, de artesanato, de pescas, de consumo e de solidariedade social; c) limites quanto ao número de votos a atribuir a cada cooperador/membro investidor -três, em cooperativas até 50 cooperadores, e cinco, em caso de cooperativas com mais de 50 cooperadores; d) limites quanto às matérias objeto de deliberação pela assembleia geral- em deliberaçôes previstas nas alíneas g), h), i) e j), do art. $38 .^{\circ}$ do CCoop, cada cooperador/membro investidor dispóe apenas de um voto (funciona, pois, exclusivamente, a regra geral constante do art. $40 .^{\circ}$, n. $^{\circ}$ 1, do CCoop, ou seja, «um membro, um voto»); e) por fim, limites para os membros investidores - cada membro investidor não pode ter direitos de voto superiores a 10\% do total de votos dos cooperadores e os membros investidores não podem, no total, ter direitos de voto superiores a $30 \%$ do total de votos dos cooperadores (art. $41 .^{\circ}$, n. ${ }^{\circ}$ 7, do CCoop ${ }^{29}$.

Tal significa que não é permitido, no estado atual da legislação cooperativa portuguesa, o voto plural nas cooperativas de solidariedade social, impondo-se uma alteraçáo no sentido da sua admissibilidade neste ramo cooperativo, tendo em conta a heterogeneidade de membros que o carateriza.

28. V. MEIRA, D. \& RAMOS, M.E.: “Artigo 40."”. In Código Cooperativo Anotado (Coord. MEIRA, D. \& RAMOS, M.E.), Almedina, Coimbra, 2018, pp. 230-234.

29. V. MEIRA, D. \& RAMOS, M.E.: "Artigo 41.o". In Código Cooperativo Anotado (Coord. MEIRA, D. \& RAMOS, M.E.), Almedina, Coimbra, 2018, pp. 235-240. 


\subsection{Especificidades do regime económico decorrentes do fim mutualístico desinteressado ou altruísta das cooperativas de solidariedade social}

Nas cooperativas de solidariedade social é proibida a distribuição de excedentes entre os membros, o que significa que todos os excedentes reverterão, obrigatoriamente, para reservas (artigo $7^{\circ}$ do Decreto-Lei no 78/98, de 15 de janeiro).

Esta impossibilidade de distribuir excedentes resulta do facto de estas cooperativas desenvolverem a sua atividade principalmente no interesse da comunidade, guiadas pelos valores do altruísmo e da solidariedade, ou seja, prosseguirem um fim mutualístico desinteressado ou altruísta.

O regime jurídico dos excedentes e seu retorno aos cooperadores assenta no pressuposto de uma cooperativa que prossegue um fim mutualístico principalmente ou exclusivamente interessado ou egoísta.

Efetivamente, os excedentes são os resultados positivos que decorrem da prossecução do escopo mutualístico pela cooperativa, correspondendo à diferença entre as receitas e os custos das operaçóes que a cooperativa desenvolve com os seus membros cooperadores. Trata-se de um valor provisoriamente pago a mais pelos cooperadores à cooperativa ou pago a menos pela cooperativa aos cooperadores, como contrapartida da participaçáo destes na atividade da cooperativa ${ }^{30}$.

A regra que consta do Código Cooperativo é a de que os excedentes poderão retornar aos cooperadores (n. 1 do art. $100 .^{\circ}$ do CCoop). O retorno de excedentes funcionará como uma correção a posteriori, através da qual se devolverá, a quem formou o excedente, a diferença entre o preço praticado e o custo, ou a diferença entre as receitas líquidas e os adiantamentos laborais pagos, diferença esta determinada com exatidão no final de cada exercício.

A distribuição do retorno entre os cooperadores será proporcional às operaçóes feitas por cada um deles com a cooperativa, no referido exercício. Sendo os excedentes, resultantes de operaçóes da cooperativa com os seus cooperadores, compreende-se, assim, que, quando ocorra o retorno, ele corresponda ao volume dessas operaçóes e não ao número de títulos de capital que cada um detenha.

Não há, todavia, um direito subjetivo ao retorno dos excedentes. O princípio cooperativo da participação económica dos membros (art. 3. ${ }^{\circ}$ do CCoop) aponta três destinos possíveis para os excedentes: $1 .^{\circ}$ "desenvolvimento das suas cooperativas"; $2 .^{\circ}$ "apoio a outras atividades aprovadas pelos membros»; $3 .^{\circ}$ "distribuição dos excedentes em benefício dos membros na proporção das suas transações com a 
cooperativa». A legislação cooperativa não impóe, por isso, às cooperativas a obrigatoriedade de retornar os excedentes aos cooperadores.

Neste contexto, nas cooperativas de solidariedade social proíbe-se o retorno dos excedentes. Esta opção legislativa contribui para um melhor autofinanciamento da cooperativa $^{31}$.

Note-se que esta impossibilidade de fazer retornar os excedentes aos cooperadores implica que as reservas livres criadas com os excedentes anuais líquidos que remanesçam (art. 98. ${ }^{\circ}$ do CCoop) não serão em caso algum repartíveis. Sendo assim, quando o cooperador sai da cooperativa de solidariedade social, por demissão ou por qualquer outra via, não terá direito à quota-parte das reservas não obrigatórias repartíveis, de que se fala no $n .^{\circ} 2$ do art. $89 .^{\circ}$ do CCoop.

Este fim mutualista desinteressado ou altruísta prosseguido pelas cooperativas de solidariedade social implica que o princípio da devolução desinteressada seja mais intenso nestas cooperativas. Efetivamente, em caso de liquidação de uma cooperativa de solidariedade social, a que náo suceda outra entidade cooperativa do mesmo ramo, o saldo de todas as reservas (obrigatórias ou voluntárias) reverte para outra cooperativa de solidariedade social, preferencialmente do mesmo município, a determinar pela federação ou confederação representativa da atividade principal da cooperativa (art. 8. ${ }^{\circ}$ do Decreto-Lei n. ${ }^{\circ} 7 / 98$, de 15 de janeiro).

Deste modo, o regime económico das cooperativas de solidariedade social, tal como está previsto no ordenamento jurídico português, mostra-se adequado às especificidades do fim mutualista desinteressado ou altruísta por elas prosseguido ${ }^{32}$.

\section{Conclusóes}

As cooperativas de solidariedade social inserem-se num movimento de reinvenção do modelo cooperativo iniciado em Itália, em 1990, com as cooperativas sociais italianas, movimento este que conduziu ao surgimento de cooperativas com um objetivo centrado, predominantemente ou exclusivamente, na prossecução de fins de interesse geral.

O fim mutualístico das cooperativas não se circunscreve à satisfação das necessidades dos seus membros (fim mutualístico interessado ou egoísta), devendo atender,

31. V. MEIRA, D.: “Artigo 100.o”. In Código Cooperativo Anotado (Coord. MEIRA, D. \& RAMOS, M.E.), Almedina, Coimbra, 2018, pp. 539-547.

32. V. MEIRA, D.: "Artigo 114. ${ }^{\circ}$ ". In Código Cooperativo Anotado (Coord. MEIRA, D. \& RAMOS, M.E.), Almedina, Coimbra, 2018, pp. 606-610. 
igualmente, aos interesses da comunidade onde a cooperativa desenvolve a sua atividade (fim mutualístico desinteressado ou altruísta).

As cooperativas de solidariedade social portuguesas prosseguem, a título principal ou exclusivo, um fim mutualístico desinteressado ou altruísta, que o legislador designa de «fins de solidariedade social».

Estas cooperativas caraterizam-se por uma heterogeneidade de membros, que o legislador agrupa em duas categorias: os membros efetivos e os membros honorários.

Impóe-se uma revisitaçáo dos conceitos de membro efetivo e de membro honorário, de forma a adequá-los à realidade atual das cooperativas de solidariedade social, com destaque para o papel cada vez mais relevante que o voluntariado social assume nestas entidades. Nada impede que uma cooperativa de solidariedade social enquadre uma organização promotora de voluntários, os quais se assumem como os membros de referência da cooperativa, devendo ser integrados na categoria dos membros efetivos. Acresce que o conceito de membro honorário deverá ser alargado de forma a poder abranger a nova categoria dos membros investidores, introduzida na reforma de 2015 do Código Cooperativo, bem como os investidores sociais, que assumem uma relevância cada vez maior na promoção e sustentabilidade destas entidades.

Impóe-se, ainda, uma alteração legislativa que elimine as restriçóes à participação plena dos membros honorários nas assembleias gerais das cooperativas de solidariedade social. Devem os membros honorários, pela importância crescente que vêm assumindo nestas cooperativas, ter o direito de voto e de eleger e ser eleitos para os órgãos sociais da cooperativa. Só assim se cumpre o princípio cooperativo da gestão democrática pelos membros.

Finalmente, de forma a conciliar os interesses destas diferentes categorias de membros, impóe-se a admissibilidade do voto plural nas cooperativas de solidariedade social, eliminando as restriçóes previstas no art. $41 .^{\circ}$ do CCoop quanto a este ramo cooperativo.

Todas estas alteraçóes legislativas são essenciais para que a cooperativa de solidariedade social prossiga, de forma eficaz, o seu fim mutualístico desinteressado ou altruísta.

Em matéria de regime económico, o quadro jurídico atual das cooperativas de solidariedade social mostra-se adequado às especificidades dos fins por elas prosseguidos, que fundamentam a proibição do retorno dos excedentes e tornam mais intenso o princípio da devolução desinteressada. 


\section{Bibliografia}

ALMEIDA, F. \& SANTOS, F.: "Portugal Inovação Social: na encruzilhada dos tempos", Cooperativismo e Economia Social, n. ${ }^{\circ} 39$, 2017, pp. 443-462.

ANDRADE, M.: Teoria Geral da Relação Jurídica, vol. I - Sujeitos e Objecto, Coimbra Editora, Coimbra, 1997.

CATARINO, A.: "Prática do voluntariado. Economia Social na prática", Revista ESEconomia Social. Leituras e Debates, n. ${ }^{\circ}$ 2, Agosto 2018. www.revista-es.info.

FAJARDO, G. \& MEIRA, A.: "Chapter 3- Cooperative Financial Structure. Commentary". In Principles of European Cooperative Law. Principles, Commentaries and National Reports (FAJARDO, G., FICI, A., HENRŸ, H., HIEZ, D., MEIRA, D., MÜNKNER, H. \& SNAITH, I), Intersentia, Cambridge, 2017, pp. 73-95. DOI: https://doi.org/10.1017/9781780686073

FAJARDO, G.: "Artigo 20.". In Código Cooperativo Anotado (Coord. MEIRA, D. \& RAMOS, M.E.), Almedina, Coimbra, 2018, pp. 122-128.

FAUQUET, G.: O Sector Cooperativo. Ensaio sobre o lugar do homem nas instituiçōes cooperativas e destas na economia (tradução de F. Pinto), Livros Horizonte, Lisboa, 1980.

FERNANDES, T.: "Artigo 4.o". In Código Cooperativo Anotado (Coord. MEIRA, D. \& RAMOS, M.E.), Almedina, Coimbra, 2018, pp. 37-42.

FERREIRA, F.: "O voluntariado e a promoção do voluntariado em Portugal", Cooperativismo e Economia Social, n. ${ }^{\circ}$ 36, 2017, pp. 305-316.

FICI, A.: "La funzione sociale delle cooperative: note di diritto comparato". In Verso un Diritto Dell' Economia Sociale. Teoria. Tendenze e Prospettive Italiane ed Europee, Editoriale Scienttifica, Napoli, 2016, pp. 241- 263.

FICI, A.: "Chapter 1. Definition and Objectives of Cooperatives. Commentary". In Principles of European Cooperative Law. Principles, Commentaries and National Reports (FAJARDO, G., FICI, A., HENRŸ, H., HIEZ, D., MEIRA, D., MÜNKNER, H. \& SNAITH, I), Intersentia, Cambridge, 2017, pp. 19-45. DOI: https://doi.org/10.1017/9781780686073

FICI, A.: "Artigo 21.o". In Código Cooperativo Anotado (Coord. MEIRA, D. \& RAMOS, M.E.), Almedina, Coimbra, 2018, pp. 129-134.

HIEZ, D.: "The general interest cooperatives: a challenge for cooperative law", IJCLInternational Jounal of Cooperative Law, n. ${ }^{\circ}$ I, 2018, pp. 93-109. 
LEITE, J.Z.: "Artigo 6."”. In Código Cooperativo Anotado (Coord. MEIRA, D. \& RAMOS, M.E.), Almedina, Coimbra, 2018, pp. 45-51.

LOPES, L.: "Breves nótulas sobre o "novo estatuto" das Instituiçôes Particulares de Solidariedade Social no Direito nacional e no Direito da União Europeia", Cooperativismo e Economia Social, n. ${ }^{\circ}$ 37, 2018, pp. 139-164.

MARGADO, A.: "SCIC, Société coopérative d'intérêt collectif”, RECMA-Revue Internationale de l'économie sociale, n. ${ }^{\circ}$ 284, 2002, pp. 19-30.

MEIRA, D.A.: "A Lei de Bases da Economia Social Portuguesa: do projeto ao texto final”, CIRIEC-España, Revista Jurídica de Economia Social y Cooperativa, n. 24 , 2013, pp. 21-52.

MEIRA, D.A.: "Reflexôes em torno do regime jurídico da reserva de educação e formação cooperativas". In O Pensamento Feminino na Construção do Direito Cooperativo (Coord. FERRAZ TEIXEIRA, M.), Vincere Editora, Brasília, 2017, pp. 57-72.

MEIRA, D.: "O princípio da participação económica dos membros à luz dos novos perfis do escopo mutualístico", Boletín de la Asociación de Derecho Cooperativo, n. ${ }^{\circ}$ 53, 2018, pp. 107-137.

DOI: http://dx.doi.org/10.18543/baidc-53-2018pp107-137

MEIRA, D.: "Artigo 100.o". In Código Cooperativo Anotado (Coord. MEIRA, D. \& RAMOS, M.E.), Almedina, Coimbra, 2018, pp. 539-547.

MEIRA, D.: "Artigo 114. o". In Código Cooperativo Anotado (Coord. MEIRA, D. \& RAMOS, M.E.), Almedina, Coimbra, 2018, pp. 606-610.

MEIRA, D.: "The Portuguese Social Solidarity Cooperative versus The PECOL General Interest Cooperative", International Journal of Cooperative Law, n. ${ }^{\circ} 2,2019$, pp. $57-71$.

MEIRA, D.: "Identidade cooperativa, admissão e demissão dos cooperadores. Realidades convergentes no direito português". In Direito Cooperativo e Identidade Cooperativa (Coord. MIRANDA, J., SOUSA, L. \& GADEA, E.), Brazil Publishing., Curitiba, 2019, pp. 71-96.

MEIRA, D. \& RAMOS, M.E.: "Artigo 40. o". In Código Cooperativo Anotado (Coord. MEIRA, D. \& RAMOS, M.E.), Almedina, Coimbra, 2018, pp. 230-234.

MEIRA, D. \& RAMOS, M.E.: "Artigo 41.o". In Código Cooperativo Anotado (Coord. MEIRA, D. \& RAMOS, M.E.), Almedina, Coimbra, 2018, pp. 235-240.

MEIRA, D. \& RAMOS, M.E.: "Social entrepreneurship: legislative contributions", RED. Revista Eletrónica de Direito, n. ${ }^{\circ} 2$ (Vol. 19), 2019, pp. 136- 162.

DOI: https://doi.org/10.24840/2182-9845_2019-0002_0006

MÜNKNER, H.: "How co-operative are social co-operatives?", CES - Cooperativismo e Economía Social, n. ${ }^{\circ}$ 38, 2016, pp. 33-75. 
OLIM, A.C.: "Artigo 117.o". In Código Cooperativo Anotado (Coord. MEIRA, D. \& RAMOS, M.E.), Almedina, Coimbra, 2018, pp. 621-623.

RODRÍGUEZ, A. \& ORTEGA, A.: "Algunas consideraciones sobre las cooperativas de iniciativa social en el marco del fomento de empleo y la inserción laboral. una perspectiva jurídico-económica", CIRIEC-España, Revista Jurídica de Economía Social y Cooperativa, n. ${ }^{\circ}$ 19, 2008, pp. 57-78.

SARAIVA, R.: "As instituiçóes particulares de solidariedade social”. In Organização Administrativa: novos actores, novos (Coord. GOMES, C.A., NEVES, A.F. \& TIAGO SERRÃO), Vol. II. Lisboa: AAFDL Editora, Lisboa, pp. 69-97.

SNAITH, I.: "Chapter 2. Cooperative Governance. Commentary". In Principles of European Cooperative Law. Principles, Commentaries and National Reports (FAJARDO, G., FICI, A., HENRŸ, H., HIEZ, D., MEIRA, D., MÜNKNER, H. \& SNAITH, I), Intersentia, Cambridge, 2017, pp. 47-72.

DOI: https://doi.org/10.1017/9781780686073

THOMAS, A.: "The Rise of Social Cooperatives in Italy", Voluntas: International Journal of Voluntary and Nonprofit Organizations, n. ${ }^{\circ}$ 15(3), 2004, pp 243-263, http://dx.doi.org/10.1023/B:VOLU.0000046280.06580.d8. 